\title{
Experimentos de Calorimetria em Cursos Universitários
}

\author{
Calorimetry Experiments in University Courses \\ Mauro Rogerio Cosentino*10, Lucas Rios ${ }^{2}$ \\ ${ }^{1}$ Universidade Federal do ABC, Santo André, SP, Brasil
}

\begin{abstract}
Recebido em 03 de Julho de 2019. Revisado em 13 de Setembro de 2019. Aceito em 16 de Setembro de 2019.
Neste trabalho investigamos em detalhes o experimento de calorimetria tipicamente realizado em cursos universitários. A motivação foi a consistente ocorrência de problemas na determinação por parte dos(as) estudantes do calor específico de uma peça de teste, muitas vezes obtendo-se valores negativos. Exploramos diversas variações do método que chamamos de "padrão" que consiste em testar medir o calor específico de uma peça metálica que é colocada para entrar em equilíbrio térmico com uma amostra de água dentro de um calorímetro simples. Além deste, exploramos um método alternativo baseado no uso do efeito Joule. Os resultados indicam que uma das variações do método padrão fornece os melhores resultados. O método alternativo, contudo, obteve resultados melhores que outras variações do método padrão além de apresentar uma maior riqueza na exploração de conceitos físicos e de análise de dados.
\end{abstract}

Palavras-chave: Termodinâmica; Calorimetria; Experimento; Efeito Joule.

In this work we investigated in detail a calorimetry experiment often executed in university courses. The motivation was the consistent occurrence of issues regarding the determination of the specific heat of a test part by the students, which often obtained negative values. We explored many variations of the "standard" method, as we called it, which consisted of measuring the specific heat of a metal part by having it reach the thermal equilibrium with a water sample within a simple calorimeter. Besides this method, we also explored an alternative one based on the Joule effect. The results show that one of the variations of the standard method to be the one that yields the best results. However, the alternative method obtained better results than some of the variations of the standard method and is also richer in the exploration of physical concepts and data analysis.

Keywords: Thermodynamics; Calorimetry; Experiment; Joule effect.

\section{Introdução}

Em cursos de termodinâmica básica um dos mais comuns tópicos de ensino da disciplina é o de Calorimetria [1] [2]. Este tópico é importante tanto pelos seus aspectos conceituais, como de demonstração experimental, pela relativa facilidade de se encontrar os elementos necessários para experimentos simplificados. Do ponto de vista teórico são apresentados os conceitos de conservação de energia, capacidade térmica e calor específico que são fundamentais para, por exemplo, introduzir a primeira lei da termodinâmica e suas aplicações em gases ideais. Experimentalmente, além de se conseguir materiais com custos relativamente baixos, a simplicidade dos diversos arranjos possíveis torna o experimento factível em praticamente qualquer laboratório didático. Em geral é necessário apenas um recipiente com alguma capacidade de isolamento térmico, água, uma fonte de calor ou de refrigeração, termômetros e nos arranjos em que se busca determinar o calor específico de um material, uma amostra deste material (geralmente latão ou alumínio). É sobre este último caso que nos debruçamos neste trabalho.

*Endereço de correspondência: mauro.cosentino@ufabc.edu.br

\section{Contextualização do Problema}

O procedimento experimental típico baseia-se na troca de calor entre a amostra de material a ter seu calor específico determinado com uma amostra de água. Para isso colocam-se as duas amostras inicialmente a temperaturas distintas e conhecidas e observa-se então a temperatura de equilíbrio, que é obtida monitorando-se a temperatura da água. Baseado no princípio de conservação de energia todo o calor que sai de uma das amostras deve ser absorvida pela outra na situação ideal em que o sistema é isolado. O isolamento completo se obtém através de um calorímetro idealizado, que não absorve calor, nem permite que haja trocas de calor entre o sistema e o ambiente que o cerca. Portanto, na situação ideal tem-se:

$$
Q_{a ́ g u a}+Q_{\text {material }}=0
$$

onde $Q_{a ́ g u a}$ e $Q_{\text {material }}$ são, respectivamente, o calor cedido (absorvido) pela água e o calor absorvido (cedido) pela amostra de material em teste. No entanto os próprios roteiros experimentais indicam que essa situação ideal não é uma hipótese razoável, pois o objeto a ser usado como calorímetro sempre se afasta muito do ideal, seja por conta de absorver calor, seja por ser incapaz de 
impedir a troca de calor com o ambiente. A situação real então é descrita pela expressão

$$
Q_{a ́ g u a}+Q_{\text {material }}+Q_{c a l}+Q_{a m b}=0
$$

onde $Q_{c a l}$ e $Q_{a m b}$ são o calor absorvido (cedido) pelo calorímetro e o calor trocado com o ambiente respectivamente. A partir daqui os roteiros experimentais adotam como sendo uma hipótese razoável a de que $Q_{a m b}=0$, fazendo com que o calorímetro seja "semi-ideal". É fácil supor que a razoabilidade dessa hipótese tenha sido postulada simplesmente pelo fato de que tentar medir - ou ao menos estimar - $Q_{a m b}$ seja virtualmente impossível. Ao mesmo tempo é fácil - e útil do ponto de vista didático - calcular $Q_{\text {cal }}$ através da expressão:

$$
Q_{c a l}=C_{c a l}\left(T_{f}-T_{i}\right)
$$

Esse procedimento, aparentemente seguro, implica numa série de riscos de erros sistemáticos que podem comprometer a qualidade do experimento, resultando em valores muito distantes do esperado para o calor específico do material de teste, por vezes obtendo-se inclusive valores negativos para essa grandeza, o que resulta em absurdo significado físico. As principais fontes de erro neste caso, referem-se justamente aos dois termos adicionais da equação 2 em relação à 1 e às hipóteses adotadas para se dar conta delas. No caso de $Q_{\text {cal }}$ tanto o valor de $C_{\text {cal }}$ quanto do de $T_{i}$ podem ser fontes de erro de difícil acesso e que comprometem significativamente o resultado. É possível exemplificar analisando-se a expressão completa para o cálculo do calor específico do material $c_{M}$ (considerando $\left.Q_{a m b}=0\right)$ :

$$
\begin{gathered}
Q_{a ́ g u a}+Q_{\text {material }}+Q_{c a l}=m_{A} c_{A}\left(T_{f}-T_{A}\right)+ \\
m_{M} c_{M}\left(T_{f}-T_{M}\right)+C_{c a l}\left(T_{f}-T_{i}\right)=0 \\
\Longrightarrow c_{M}=\frac{-m_{A} c_{A}\left(T_{f}-T_{A}\right)+C_{c a l}\left(T_{f}-T_{i}\right)}{m_{M}\left(T_{f}-T_{M}\right)}
\end{gathered}
$$

Onde $m_{A}, c_{A}$ e $T_{A}$ são respectivamente a massa, o calor específico e a temperatura inicial da água, e $m_{M}$ e $T_{M}$ são respectivamente a massa e a temperatura inicial da amostra em teste. Todos os corpos (água, amostra de material e calorímetro) tem a mesma temperatura final de equilíbrio. Tipicamente neste tipo de experimento escolhe-se ou a amostra (ou peça) de material em teste ou a amostra de água para estar à temperatura ambiente e em equilíbrio inicial com o calorímetro, também à temperatura ambiente. Supondo, por exemplo, que seja a peça a estar inicialmente à temperatura ambiente em equilíbrio com o calorímetro, a equação 5 então simplificase para

$$
c_{M}=-\left[\frac{m_{A} c_{A}\left(T_{f}-T_{A}\right)}{m_{M}\left(T_{f}-T_{i}\right)}+\frac{C_{c a l}}{m_{M}}\right]
$$

No caso em que se escolhe a água estando inicialmente à temperatura ambiente e em equilíbrio com o calorímetro a equação 5 então se torna

$$
c_{M}=-\left[\frac{m_{A} c_{A}+C_{c a l}}{m_{M}}\right]\left[\frac{T_{f}-T_{i}}{T_{f}-T_{M}}\right]
$$

É possível notar que a razão entre as diferenças de temperatura em ambos os casos será sempre negativa. Isso posto nota-se para a equação 6 que, caso o valor atribuído a $C_{c a l}$ seja superestimado, pode-se obter um valor negativo para $c_{M}$, ao passo que na situação descrita pela equação 7 a superestimação de $C_{c a l}$ implica em superestimação de $c_{M}$.

Outra fonte possível de erro sistemático está na hipótese de que a temperatura inicial do calorímetro é conhecida, pois em geral o procedimento é repetido um certo número de vezes para se ter amostras significativas dos valores de $C_{c a l}$ e de $c_{M}$, obtidos pelas médias das repetidas medidas e associando as incertezas às flutuações estatísticas destas medidas. Nestes casos, a primeira medida de temperatura inicial pode ser considerada como sendo a ambiente com segurança pois o calorímetro ainda não teria sido utilizado e portanto não teria sido submetido a aumento (diminuição) de temperatura. Nas medidas seguintes é provável que o calorímetro não tenha mais a mesma temperatura inicial da primeira medida. Com efeito é provável que todas as medidas de temperatura inicial sejam diferentes. Para eliminar esse efeito adota-se o procedimento de enxaguar o calorímetro várias vezes com água à temperatura ambiente, até que o mesmo atinja sempre a mesma temperatura inicial idêntica à do ambiente. No entanto a realização pouco cuidadosa desta etapa, seja por desatenção dos estudantes ou pela pressão do tempo de duração da aula, pode levar ao descontrole em relação ao valor da temperatura inicial do calorímetro. Esse descontrole não permite, por exemplo, a simplificação da equação 5 para a 6. Isso implicaria numa variação de temperatura menor que a presumida para o calorímetro, tendo efeito similar à subestimação do valor de $C_{c a l}$ e consequente superestimação do valor de $c_{M}$ pela equação 6 ou subestimação pela equação 7

Essas e outras fontes de incerteza sistemática precisam ser melhor compreendidas e controladas para que se possa estabelecer roteiros de aula confiáveis para que os objetivos didáticos destes experimentos sejam atingidos com segurança e foi com isso em mente que esse trabalho foi realizado.

Numa tentativa de minimizar os efeitos mencionados idealizamos um método experimental que consiste em aquecer uma amostra d'água dentro do calorímetro através do efeito Joule, semelhante ao empregado em [3]. Inicialmente se faz o aquecimento apenas com água e depois novamente com a peça. Considerando-se esta situação pode-se encontrar a seguinte expressão para a temperatura em função do tempo transcorrido:

$$
T(t)=\frac{P}{C_{T}} t+T_{0}
$$


Onde $P$ é a potência dissipada pelo resistor imerso na água via efeito Joule, $C_{T}$ é a capacidade térmica total do conjunto, $t$ é o tempo transcorrido (considerando o instante inicial em zero) e $T_{0}$ a temperatura inicial. Essa expressão pode ser usada para os dois momentos do experimento - sem e com a peça incluída - de forma que se obtenha dois valores para a capacidade térmica do conjunto. Escolhendo cuidadosamente a quantidade de água para que se obtenha o mesmo valor de $C_{c a l}$ em ambas as situações e através do coeficiente angular de ajustes lineares aos pontos experimentais é possível se obter o calor específico da peça como sendo

$$
c_{M}=\frac{1}{m_{M}}\left(P \Sigma-\Delta m_{A} c_{A}\right)
$$

onde $\Delta m_{A}$ é a diferença na massa de água entre as duas partes, que é o ajuste necessário para se garantir que $C_{c a l}$ seja a mesma nas duas etapas. O termo $\Sigma$ é definido por

$$
\Sigma=\frac{1}{\alpha_{2}}-\frac{1}{\alpha_{1}}
$$

$\operatorname{com} \alpha_{2}<\alpha_{1} \mathrm{e}$

$$
\alpha_{i}=\frac{P}{C_{T_{i}}}
$$

Este trabalho então está organizado da seguinte forma: na seção 3 procura-se elencar todas as possíveis fontes de erros sistemáticos e as hipóteses necessárias para testar seus limites; na seção 4 é apresentado o desenvolvimento das metodologias experimentais orientadas aos problemas elencados; na seção 5 apresenta-se a análise dos dados obtidos e seus resultados e culminando com as discussões e conclusões presentes na seção 7

\section{Fontes de erro e hipóteses associadas}

Como dito na introdução duas das principais fontes de erro são a estimativa da capacidade térmica do calorímetro e a temperatura inicial dele - e da peça nos cenários em que ambos iniciam em equilíbrio com o ambiente. Mas além delas é necessário também investigar a troca de calor com o ambiente, tentando minimamente quantificar esse efeito.

\subsection{Capacidade térmica do calorímetro}

A capacidade térmica do calorímetro precisa ser medida de maneira independente às medidas de calor específico. $\mathrm{O}$ risco neste método é de se proceder com diferenças sistemáticas entre os procedimentos para a medida de $C_{c a l}$ e ao de $c_{M}$. Uma hipótese levantada refere-se à quantidade de água utilizada em cada processo. Como a troca de calor entre a água e o calorímetro se dá pelo contato entre ambos, quantidades de água significativamente diferentes resultarão em superfícies de contato muito diferentes. Como os calorímetros são compostos de materiais isolantes, não ocorre condução significativa da parte em contato com a água para o restante do calorímetro. Desta forma, a região do calorímetro que efetivamente recebe (ou fornece) calor da (à) água varia significativamente, implicando em capacidades térmicas muito diferentes para um mesmo calorímetro.

A figura 1 representa esquematicamente este efeito.

Essa hipótese foi testada com sucesso conforme descrito mais adiante no texto.

\subsection{Trocas de calor com o ambiente}

Essa é possivelmente a fonte de erro sistemático de maior impacto, seja por conta das quantidades de calor relativamente elevadas em termos do total de troca de calor, seja porque, justamente, é difícil quantificar esse efeito e mesmo obter métodos confiáveis para eliminá-lo. Uma das hipóteses associadas - e que foi efetivamente testada - implica que o efeito das perdas é maior quando a água é o corpo que deverá fornecer (absorver) calor, quando comparada à opção de se variar a temperatura inicial da peça em teste. Uma hipótese adicional é a de que esse efeito é especialmente importante quando se usa água quente, pois há evaporação de parte da água adicionada e a perda de energia se dá também por convecção, implicando na máxima perda de calor possível.

Na situação em que a peça é colocada inicialmente a uma temperatura diferente da do ambiente - tanto faz se mais quente ou mais fria - a água dentro do calorímetro funcionaria como uma "camada adicional de isolamento", fazendo com que a potência dissipada (absorvida) para (do) ambiente seja ainda menor. Ainda assim a troca pode não ser desprezível.

Existem métodos que podem estimar a perda de calor para o ambiente de maneira razoavelmente precisa [6], mas dependendo do escopo do experimento e do tempo disponível em aula, pode não ser exequíve ${ }^{1}$

\subsection{Temperatura de equilíbrio}

Um dos pontos cruciais do experimento é determinar em que momento se atingiu o equilíbrio entre os componentes do sistema (água e calorímetro ou água e calorímetro e peça). É especialmente difícil estimar esse valor quando
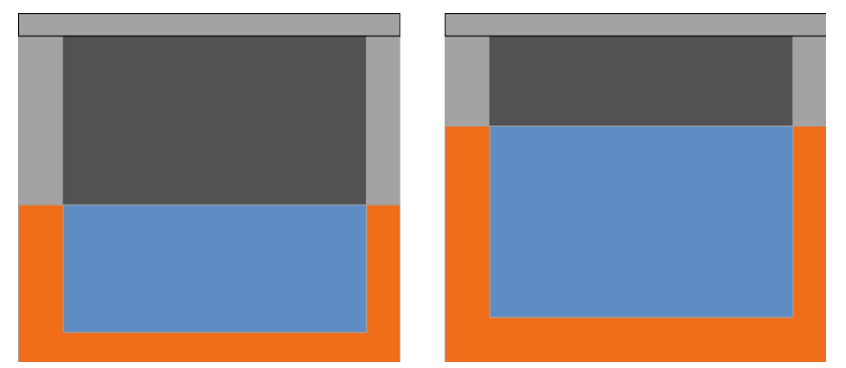

Figura 1: Calorímetro com diferentes volumes de água, resultando em diferentes estimativas de capacidade térmica.

\footnotetext{
$\overline{{ }^{1} \text { Em experimentos com tempo de aula suficiente a abordagem }}$ utilizada na referência deve ser considerada.
} 
a temperatura da água está muito distante da temperatura ambiente pois a variação ocorre de maneira muito mais rápida num cenário como esse. Acredita-se que esse efeito possa ser diluído fazendo-se algumas repetições do procedimento, pois em princípio, a temperatura final será por vezes subestimada e em outras superestimadas, de forma que diferentes medidas acabam compensando erros individuais. O perigo aqui é adotar algum procedimento que tenha tendência sempre numa mesma direção, impedindo a compensação.

\subsection{Termalização do sistema no método de efeito Joule}

No método que utiliza o efeito Joule, uma possível fonte de erro sistemático é o fato da água receber o calor dissipado pela resistência localmente. Desta forma, a mistura pode ficar heterogênea em sua distribuição de temperaturas, não havendo equilíbrio global. Esse fato pode corresponder a leituras equivocadas de temperatura. Um sintoma deste problema - quando se usa um termopar - é a ocorrência de saltos na leitura de temperatura, indicando momentos de descontinuidade na tendência de aumento da mesma como função do tempo.

Para minimizar esse efeito é necessário algum tipo de agitação da água, mas é preciso ter cuidado para não causar derramamento da água e/ou molhar uma superfície do calorímetro muito maior do que aquela que seria tocada pelo volume de água em repouso, devido aos motivos mencionados na seção 3.1

\section{Metodologias}

A seguir são apresentadas as duas metodologias utilizadas para a determinação do calor específico usando-se o mesmo calorímetro e tipo de amostra.

\subsection{Método padrão}

Pelo método padrão o experimento foi executado em duas partes. A primeira para determinar a capacidade térmica do calorímetro e a segunda o calor específico da peça metálica.

\subsubsection{Capacidade Térmica}

Uma das dificuldades neste tipo de experimento pode ser o fato de que o calorímetro não tenha um valor esperado para sua capacidade térmica, por ser um objeto composto, semelhante a uma garrafa térmica, como é o caso na UFABC, que não possui qualquer valor estipulado pelo fabricante.

Assim, com o intuito de se obter uma estimativa, dois métodos foram explorados para calcular a capacidade térmica. Um foi o método que vem sendo adotado na disciplina de Fenômenos Térmicos da UFABC [4], no qual se utiliza água quente, sendo uma concha de água a quantidade inserida no calorímetro para que se atinja o equilíbrio do sistema. O calorímetro é suposto estar inicialmente à temperatura ambiente. A temperatura inicial da água é medida imediatamente após a colocação da mesma dentro do calorímetro e considera-se o equilíbrio quando a leitura de temperatura obtida a partir de um termopar mantém-se estável por vários segundos (tipicamente $>5 \mathrm{~s}$ ). As medidas foram repetidas cinco vezes. Após cada repetição, o calorímetro era enxaguado com água à temperatura ambiente inúmeras vezes até que este voltasse a estar em equilíbrio térmico com o ambiente. No segundo método foi utilizado água gelada, mas o restante do procedimento se mantém inalterado.

Em ambos os casos a determinação da massa de água foi obtida pesando-se o calorímetro com a quantidade de água utilizada em cada uma das medidas. Antes das medidas serem iniciadas o calorímetro foi pesado vazio na mesma balança em que foram feitas as demais pesagens.

\subsubsection{Calor Específico}

Para determinar o calor específico das peças de latão, utilizou-se quatro implementações distintas do método considerado padrão. Primeiro, utilizamos o método definido no roteiro em uso na UFABC, que consiste em colocar a peça metálica dentro do calorímetro com ambos inicialmente à temperatura ambiente. Em seguida adiciona-se água quente ao calorímetro até que o sistema entre em equilíbrio. Segundo, com a mesma ideia de utilizar o calorímetro e peça de metal a temperatura ambiente, utilizou-se água gelada para alterar a temperatura do sistema.

A partir do terceiro método, o sistema inicial passou a ser o calorímetro e uma concha de água à temperatura ambiente. E a peça ou quente (método três) ou fria (método quatro). Em todos os métodos foram feitas cinco repetições, como no caso da capacidade térmica do calorímetro.

Em todos os casos a determinação da massa de água seguiu procedimento semelhante ao descrito na seção 4.1.1. tendo a peça de metal também sido pesada anteriormente às medidas na mesma balança.

\subsection{Método usando Efeito Joule}

Para esse método utilizamos um arranjo semelhante ao esquematizado na figura 2 Com uma fonte de alimentação, ligamos um resistor de $21 \pm 1 \Omega$. Além do multímetro ligado ao termopar, para termos precisão maior que o do monitor da fonte de tensão, usamos um multímetro em paralelo e outro em série para as medidas de tensão e corrente respectivamente. A tensão a ser usada seria em torno de $15 \mathrm{~V}$ e a corrente $0.65 \mathrm{~A}$. Com o resistor dentro do calorímetro, fizemos três experimentos. Dois apenas com água, sendo $60 \mathrm{ml}$ e $120 \mathrm{ml}$ de volume. O terceiro contava com uma peça cilíndrica de latão e água, de tal forma que o volume total de ambos fosse $120 \mathrm{ml}$. Assim, a área de contato entre a água e o calorímetro seria a mesma do segundo experimento. Pesamos a água sem a 
peça para saber o quanto fora adicionado. Cada experimento foi filmado (enquadrando-se os três multímetros), a partir da temperatura de $24^{\circ} \mathrm{C}$ até $33^{\circ} \mathrm{C}$.

As duas medidas sem a peça tiveram por objetivo testar a hipótese da dependência do valor estimado para $C_{c a l}$ com a superfície interna de contato da água com o calorímetro - portanto, com o volume - conforme discutido na seção 3.1

Alguns cuidados foram tomados antes de se iniciar a tomada de dados. O primeiro deles foi o de ter certeza de que o calorímetro e a água estavam em equilíbrio térmico. Para isso agitou-se suavemente o conjunto por alguns segundos e esperou-se mais um certo tempo para verificar se a temperatura medida pelo termopar se mantinha. Esse processo tomou cerca de $30 \mathrm{~s}$ no total.

O segundo cuidado antes de iniciar a tomada de dados foi a de se ligar a fonte antes de se mergulhar o resistor na água, deixando o fora da mesma por algum tempo ( $\sim 10 \mathrm{~s})$, para que qualquer regime transiente na potência dissipada fosse ultrapassado. Além disso, desprezou-se o primeiro $1{ }^{\circ} \mathrm{C}$ de variação na temperatura.

Para a tomada de dados foi utilizado um telefone portátil do tipo smartphone com câmera de vídeo acoplada. O vídeo foi iniciado imediatamente após o resistor (já com corrente) ser submerso na água. Durante todo o procedimento o calorímetro foi contínua e suavemente agitado através de movimentos circulares na horizontal. Essa agitação é necessária para garantir que a água mantenha a mesma temperatura em todo o seu volume durante todo o tempo.

\section{Análise de dados}

Seguindo a lógica das seções anteriores a análise de dados é apresentada nesta seção em duas partes referentes aos dois diferentes métodos adotados.

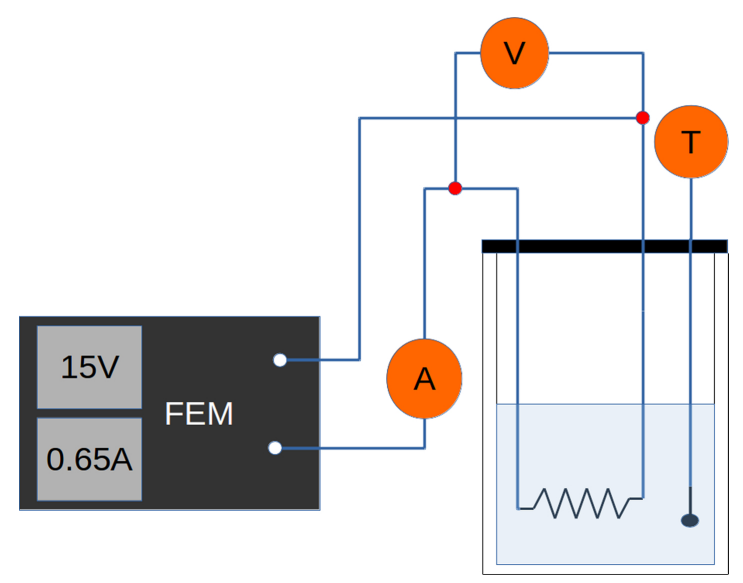

Figura 2: Esquema do método de efeito Joule. Sendo $A$, o amperímetro em série, $\mathrm{V}$ o voltímetro em paralelo com o resistor, que se encontra submerso dentro do calorímetro. FEM, a fonte e T o termopar independente.

\subsection{Método padrão: primeira parte (capacidade térmica do calorímetro)}

Os dados coletados pelo procedimento experimental por este método estão dispostos nas tabelas numeradas de 1 a 6. As tabelas $1 \mathrm{e} 2$ referem-se às medidas para estimativas de $C_{c a l}$, usando amostras de água gelada e de água quente, respectivamente.

O cálculo de $C_{c a l}$ é feito para cada uma das medidas (linhas) das referidas tabelas empregando-se a equação

$$
C_{c a l}=-\frac{m_{A} c_{A}\left(T_{f}-T_{A}\right)}{T_{f}-T_{i}}
$$

onde as variáveis significam o mesmo que na equação 5 . Assim como nas equações anteriores, a hipótese aqui é de

Tabela 1: Dados para o calorímetro com água gelada e sem peça, com $T_{i}, T_{A}$ e $T_{f}$ definidos na equação 5 . Incertezas nas temperaturas são sempre $1{ }^{\circ} \mathrm{C}$ e nas massas $1 \mathrm{~g}$.

\begin{tabular}{cccc}
\hline$T_{i}\left[{ }^{\circ} \mathrm{C}\right]$ & $T_{A}\left[{ }^{\circ} \mathrm{C}\right]$ & Massa total $[\mathrm{g}]$ & $T_{f}\left[{ }^{\circ} \mathrm{C}\right]$ \\
\hline 23 & 5 & 187 & 7 \\
24 & 5 & 190 & 6 \\
23 & 5 & 178 & 6 \\
24 & 5 & 192 & 6 \\
25 & 5 & 182 & 6 \\
\hline
\end{tabular}

Tabela 2: 0 mesmo que a tabela 1. mas para água quente.

\begin{tabular}{cccc}
\hline$T_{i}\left[{ }^{\circ} \mathrm{C}\right]$ & $T_{A}\left[{ }^{\circ} \mathrm{C}\right]$ & Massa total $[\mathrm{g}]$ & $T_{f}\left[{ }^{\circ} \mathrm{C}\right]$ \\
\hline 22 & 81 & 175 & 70 \\
23 & 70 & 179 & 62 \\
23 & 64 & 174 & 57 \\
25 & 59 & 178 & 54 \\
24 & 75 & 187 & 65 \\
\hline
\end{tabular}

Tabela 3: Procedimento com água quente e a peça inicialmente à temperatura ambiente. Incertezas nas temperaturas são sempre $1^{\circ} \mathrm{C}$ e nas massas $1 \mathrm{~g}$.

\begin{tabular}{cccc}
\hline$T_{i}\left[{ }^{\circ} \mathrm{C}\right]$ & $T_{A}\left[{ }^{\circ} \mathrm{C}\right]$ & Massa total $[\mathrm{g}]$ & $T_{f}\left[{ }^{\circ} \mathrm{C}\right]$ \\
\hline 27 & 81 & 244 & 74 \\
31 & 80 & 250 & 75 \\
28 & 86 & 240 & 74 \\
28 & 84 & 230 & 72 \\
28 & 88 & 240 & 74 \\
\hline
\end{tabular}

Tabela 4: Procedimento com água inicialmente à temperatura ambiente e com a peça fria. Incertezas nas temperaturas são sempre $1^{\circ} \mathrm{C}$ e nas massas $1 \mathrm{~g}$.

\begin{tabular}{cccc}
\hline$T_{i}\left[{ }^{\circ} \mathrm{C}\right]$ & $T_{M}\left[{ }^{\circ} \mathrm{C}\right]$ & Massa total $[\mathrm{g}]$ & $T_{f}\left[{ }^{\circ} \mathrm{C}\right]$ \\
\hline 26 & 3 & 245 & 22 \\
25 & 2 & 256 & 22 \\
25 & 4 & 249 & 23 \\
25 & 4 & 258 & 21 \\
25 & 3 & 255 & 21 \\
\hline
\end{tabular}


Tabela 5: Procedimento com água inicialmente à temperatura ambiente e com a peça quente. Incertezas nas temperaturas são sempre $1{ }^{\circ} \mathrm{C}$ e nas massas $1 \mathrm{~g}$.

\begin{tabular}{cccc}
\hline$T_{i}\left[{ }^{\circ} \mathrm{C}\right]$ & $T_{M}\left[{ }^{\circ} \mathrm{C}\right]$ & Massa total $[\mathrm{g}]$ & $T_{f}\left[{ }^{\circ} \mathrm{C}\right]$ \\
\hline 25 & 74 & 255 & 29 \\
25 & 68 & 248 & 27 \\
25 & 73 & 252 & 29 \\
25 & 68 & 257 & 28 \\
25 & 69 & 256 & 28 \\
\hline
\end{tabular}

Tabela 6: Procedimento com água fria e a peça inicialmente à temperatura ambiente. Incertezas nas temperaturas são sempre $1{ }^{\circ} \mathrm{C}$ e nas massas $1 \mathrm{~g}$.

\begin{tabular}{cccc}
\hline$T_{i}\left[{ }^{\circ} \mathrm{C}\right]$ & $T_{A}\left[{ }^{\circ} \mathrm{C}\right]$ & Massa total $[\mathrm{g}]$ & $T_{f}\left[{ }^{\circ} \mathrm{C}\right]$ \\
\hline 25 & 5 & 247 & 8 \\
23 & 4 & 263 & 8 \\
23 & 5 & 262 & 8 \\
24 & 4 & 254 & 8 \\
24 & 5 & 248 & 7 \\
\hline
\end{tabular}

que as perdas para o ambiente são desprezívei:2 ${ }^{2}$ A estimativa para a capacidade térmica do calorímetro é então obtida através da média das cinco medidas constantes em cada caso, e denotamos então por $\overline{C_{c a l}}$. Os resultados então obtidos para as medidas com água gelada (g) e água quente (q) são, respectivamente

$$
\begin{aligned}
& {\overline{C_{c a l}}}^{(g)}=18 \pm 3 \mathrm{~J} / \mathrm{K} \\
& {\overline{C_{c a l}}}^{(q)}=41 \pm 4 \mathrm{~J} / \mathrm{K}
\end{aligned}
$$

Esses resultados corroboram a grande discrepância que pode se obter fazendo-se medidas distintas com um mesmo calorímetro, quando usando métodos distintos (água gelada vs. água quente). As incertezas neste caso são meramente estatísticas, conforme definido em [5]. Dos resultados acima podemos inferir que o procedimento que utiliza água aquecida tem troca de calor com o ambiente maior do que aquele que utiliza água gelada. Para isso, basta adicionar um termo de troca $\delta Q$ no balanço geral de energia.

$$
\begin{aligned}
Q_{a ́ g u a} & +Q_{c a l}+\delta Q=0 \Longrightarrow \\
C_{c a l} & =-\frac{m_{A} c_{A}\left(T_{f}-T_{A}\right)+\delta Q}{T_{f}-T_{i}}
\end{aligned}
$$

Por conservação de energia o sinal de $\delta Q$ é oposto ao de $\left(T_{f}-T_{A}\right)$. Assim, se simplesmente ignorarmos o termo $\delta Q$ notamos que, quanto maior for o seu valor ${ }^{3}$ absoluto, maior será o resultado obtido para $C_{c a l}$. Considerando que estamos medindo $C_{\text {cal }}$ para o mesmo objeto com aproximadamente a mesma quantidade de água, podemos concluir que quanto maior o valor da estimativa, maior foi a troca de calor com o ambiente. Uma possível explicação

\footnotetext{
${ }^{2}$ Sem esquecer de todas as implicações em discussão

${ }^{3}$ Evidentemente limitado ao valor absoluto de $Q_{a ́ g u a}$
}

Tabela 7: Resultados de calor específico para os diferentes procedimentos e considerando os dois resultados de $\overline{C_{c a l}}$. Os valores estão em $\left[\mathrm{J} /\left(\mathrm{kg} \cdot{ }^{\circ} \mathrm{C}\right)\right]$.

\begin{tabular}{lcc}
\hline Procedimento & ${\overline{C_{c a l}}}^{(g)}$ & $\overline{C_{c a l}}(q)$ \\
\hline Água quente & $456 \pm 110$ & $66 \pm 110$ \\
Água fria & $637 \pm 158$ & $248 \pm 158$ \\
Peça quente & $364 \pm 40$ & $393 \pm 43$ \\
Peça fria & $883 \pm 131$ & $955 \pm 141$ \\
\hline
\end{tabular}

para essa diferença seria a evaporação, que é acentuada quando a água está aquecida, mas que não ocorre com a água gelada. Essa é a evidência que corrobora uma das hipóteses da seção 3.2 e sugere que o procedimento que utiliza água aquecida deve ser evitado em roteiros de aula para este tipo de experimento, pois quanto maior for a superestimação de $C_{c a l}$ maiores as chances de se obter um valor negativo (e não físico) para $c_{M}$.

\subsection{Método padrão: segunda parte (calor específico)}

Nesta segunda parte o método padrão faz então o mesmo tipo de medida que anteriormente, mas agora adicionandose a peça do material a ser testado. Neste caso específico foi utilizada uma peça de latão de massa igual a $58 \pm 1 \mathrm{~g}$. O valor tabelado para o calor específico do latão $\left(c_{M}\right)$ é de $380 \mathrm{~J} /\left(\mathrm{kg} \cdot{ }^{\circ} \mathrm{C}\right)$. Os resultados foram obtidos de maneira semelhante ao descrito na seção 5.1. onde são obtidos valores individuais de $c_{M}$ para cada linha de cada uma das tabelas 3 a 6 e depois se faz a média sobre eles para se obter $\overline{c_{M}}$. Além disso, para cada caso, foram calculados dois valores de $\overline{c_{M}}$, um para cada um dos valores de obtidos de $\overline{C_{\text {cal }}}$.

Os valores de $c_{M}$ foram calculados de acordo com a equação 6 nos casos em que a peça estava inicialmente à temperatura ambiente e de acordo com a equação 7 quando a água estava inicialmente à temperatura ambiente. Em ambas as situações o calorímetro é suposto estar inicialmente à temperatura ambiente. Os resultados obtidos em cada caso são apresentados na tabela 7

Os resultados da tabela 7 mostram que de todos os procedimentos aquele que utiliza a água inicialmente à temperatura ambiente e com a peça aquecida é o que dá resultados mais consistentes com o valor tabelado, além de ser o método mais preciso. Os métodos com a peça inicialmente à temperatura ambiente (água quente ou fria) são muito mais suscetíveis às flutuações no valor de $C_{c a l}$. É possível notar ainda que a superestimação do valor de $\bar{C}_{c a l}(q)$ para o procedimento com água quente (primeira linha) faz com que o valor obtido para o calor específico não apenas é consistente com zero, como, interpretado apenas à luz da incerteza obtida, pode ser admitido como sendo negativo, o que claramente tem significado físico absurdo. 
Nos procedimentos em que a água inicia à temperatura ambiente o efeito nos valores de $\overline{c_{M}}$ são menos suscetíveis a discrepâncias nos valores estimados de $C_{c a l}$ devido ao fato de que este valor é multiplicado pelo mesmo valor de variação térmica à qual é submetida a massa de água, como está evidente na equação 7. Assim, como a capacidade térmica da massa d'água é significativamente maior que a do calorímetro, mesmo significativas variações no valor deste último resultam em variações inferiores às incertezas calculadas para os respectivos valores de $\overline{c_{M}}$.

Assim como discutido na seção 5.1, a troca de calor sendo considerada como zero acaba superestimando os valores de $\overline{c_{M}}$ como pode ser observado nos valores à esquerda nas duas primeiras linhas da tabela 7

O caso do procedimento com a peça inicialmente a baixas temperaturas é mais difícil de se analisar. Em análise preliminar pode-se supor duas contribuições. A primeira seria que neste caso, diferentemente do que aconteceu com a peça aquecida, a troca de calor com o ambiente pode ter sido mais significativa, impondo uma superestimação dos valores obtidos para $\overline{c_{M}}$. Seriam necessárias medidas adicionais e novos métodos para se testar essa suposição.

A outra contribuição possível vem de que com a peça esfriando a água, a convecção que ocorre naturalmente com a peça quente, fica prejudicada e a água pode não ficar plenamente termalizada. Com a ponta do termopar sendo sistematicamente colocada no fundo do calorímetro ele tenderia a medir a temperatura mais baixa da mistura de água, subestimando aquilo que deveria ser a temperatura de equilíbrio. Esse problema poderia ser resolvido aplicando-se uma suave agitação mecânica do calorímetro, promovendo a termalização da amostra de água com a peça metálica. Esse procedimento não foi adotado durante essas medidas.

\subsection{Método alternativo (efeito Joule)}

Começamos com a análise dos dois conjuntos de medidas obtidos com os calorímetros contendo apenas água em quantidades diferentes. O primeiro objetivo destas medidas era obter uma medida independente de $C_{c a l}$ e que fosse independente de hipóteses acerca de temperaturas inicial e final, que são de difícil controle. Além disso procurou-se testar a hipótese de que volumes diferentes de água podem resultar em valores diferentes $C_{c a l}$.

A figura 3 mostra um gráfico com os pontos resultantes das medidas do calorímetro apenas com água: um conjunto obtido com 54 mililitros e o segundo com $108 \mathrm{ml}$. De acordo com a equação 8 a utilização de uma mesma potência em ambos as medidas resulta em coeficientes angulares de ajustes que diferem apenas pela capacidade térmica total $C_{T}$.

As capacidades térmicas totais em cada caso podem ser equacionadas como

$$
C_{T}=m_{A} c_{A}+C_{c a l}+\delta C
$$

Onde $\delta C$ é o efeito equivalente em termos de capacidade térmica resultante da troca de calor com o ambiente e em primeira aproximação admite-se que seu valor seja o mesmo para as duas medidas. A hipótese de que a potência é constante pode ser considerada aceitável pois os valores obtidos durante cada uma das duas medidas foram 9,783 W (54 ml) e 9,776 W (108 ml), uma diferença de apenas $0,07 \%$, muito menor que a incerteza de cada medida $(0,15 \mathrm{~W}$ ou $1,5 \%)$. Uma maneira de se buscar $\delta C \rightarrow 0$, é realizar as medidas num intervalo de temperatura o mais próximo possível da temperatura ambiente. Observando o $\chi^{2}$ reduzido dos ajustes na figura 3 podese concluir que as incertezas dos pontos são largamente superestimadas. As incertezas foram admitidas inicialmente como sendo $1^{\circ} \mathrm{C}$, que é o que costumeiramente se faz para leituras com termopares em multímetros com leitura de $1 \mathrm{em} 1{ }^{\circ} \mathrm{C}$. No entanto, se essa incerteza for levada estritamente, os dados só poderiam ser considerados estatisticamente independentes (não correlacionados) se fossem tomados em intervalos de no mínimo $2{ }^{\circ} \mathrm{C}$. Isso reduziria os nossos conjuntos de dados a no máximo metade dos pontos que obtivemos no mesmo intervalo de temperatura. Podemos admitir, com baixo risco - na verdade nenhum risco como veremos mais adiante - uma incerteza de $0,5{ }^{\circ} \mathrm{C}$ para cada ponto experimental. Esse foi o valor utilizado para se fazer o gráfico da figura 3 cujos $\chi^{2}$ são extremamente baixos. Portanto, mesmo $0,5{ }^{\circ} \mathrm{C}$ pode ser considerada uma estimativa elevada e por esse motivo foi utilizado uma técnica de análise explicitada mais adiante - que permite uma estimativa de valores significativamente mais baixos.

Com as incertezas utilizadas na figura 3 podemos calcular a capacidade térmica total como $C_{T}=P / \alpha$ e portanto temos

$$
\begin{aligned}
& C_{T_{v 54}}=299 \pm 27 \mathrm{~J} / \mathrm{K} \\
& C_{T_{v 108}}=538 \pm 49 \mathrm{~J} / \mathrm{K}
\end{aligned}
$$

Onde os sub-índices $v 54$ e $v 108$ correspondem aos volumes de 54 e $108 \mathrm{ml}$, respectivamente. Utilizando-se da mesma nomenclatura, as capacidades térmicas dos dois volumes de água correspondem a $c_{A} m_{A}(v 54)=226.0 \pm 0.6$ $\mathrm{J} / \mathrm{K} \mathrm{e} c_{A} m_{A}(v 108)=451.2 \pm 0.6 \mathrm{~J} / \mathrm{K}$, resultando nos valores $C_{\text {cal }}(v 54) 73 \pm 27 \mathrm{~J} / \mathrm{K}$ e $C_{\text {cal }}(v 108) 86 \pm 49 \mathrm{~J} / K$. Com estas incertezas, não é possível determinar uma diferença na capacidade térmica do calorímetro que dependa da quantidade de água utilizada. No entanto, como já foi discutido acima, as incertezas nas medidas de temperatura continuam largamente superestimadas. Utilizando a técnica discutida adiante é possível reduzir as incertezas para $\sim 0,02{ }^{\circ} \mathrm{C}$, o que resultaria em incertezas de $5 \mathrm{~J} / \mathrm{K}$ $(54 \mathrm{ml})$ e $9 \mathrm{~J} / \mathrm{K}(108 \mathrm{ml})$, o que coloca as duas medidas de $C_{c a l}$ no limite da compatibilidade, pois

$$
\begin{aligned}
C_{c a l}(v 54) & =73 \pm 5 \mathrm{~J} / \mathrm{K} \\
C_{\text {cal }}(v 108) & =86 \pm 9 \mathrm{~J} / \mathrm{K}
\end{aligned}
$$

Ou seja, embora não se possa afirmar que há um aumento de $C_{c a l}$ em função do aumento do volume de água, 


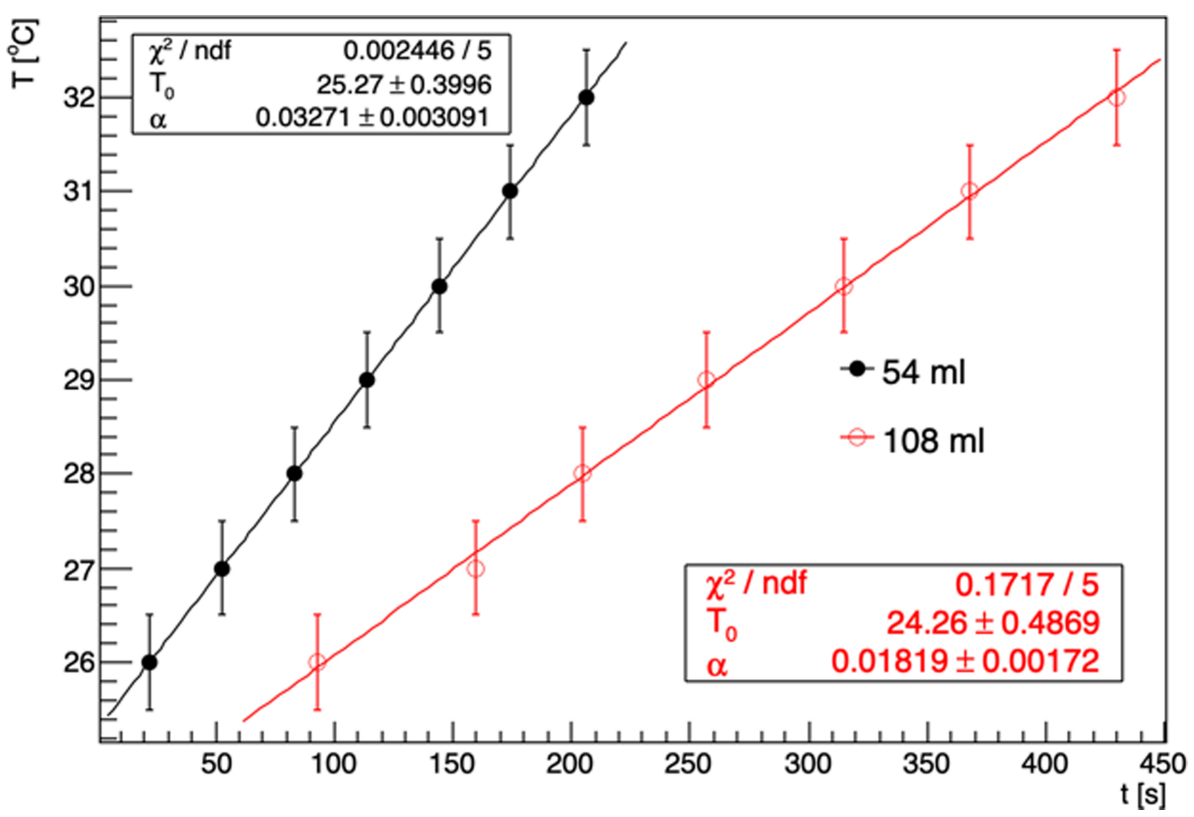

Figura 3: Evolução temporal da temperatura da água para dois volumes de água: pontos pretos sólidos (54 ml) e vermelhos vazados $(108 \mathrm{ml})$, com seus respectivos ajustes (os parâmetros de ajuste no alto à esquerda referem-se aos pontos sólidos).

os valores indicam uma tendência. Considerando que o fator preponderante na hipótese de que $C_{c a l}$ varia com a quantidade de água é a superfície de contato entre água e calorímetro, dobrar o volume de água não dobra a superfície, pois a base do "cilindro" formado pela amostra da água não se altera com o volume. Considerando o diâmetro interno do calorímetrd 4 de $\sim 48 \mathrm{~mm}$ e os volumes de água usados a superfície de contato da amostra de $108 \mathrm{ml}$ é $71 \%$ maior daquela da amostra de $54 \mathrm{ml}$. Portanto, para se ter uma resultado mais contundente para o teste da hipótese proposta de acordo com a figura 1. o ideal seria usar dois volumes de água com um fator 3 do maior para o menor - ou seja, neste caso deveria ter sido testado um volume de $\sim 180 \mathrm{ml}$.

\section{Calor específico}

Para a sequência do experimento procuramos então realizar as medidas de tal forma que tanto a medida sem a peça (estimativa para $C_{c a l}$ ) e com a peça (determinação de $c_{M}$ ) tivessem o mesmo volume total. Inicialmente colocou-se uma certa quantidade de água num béquer, procurando-se alinhar a linha d'água com a marca de 120 ml, sem usar a peça. Em seguida pesou-se o béquer com água obtendo-se a massa total de $m_{t}=144 \pm 1 \mathrm{~g}$ e depois de verter o conteúdo dentro do calorímetro, o béquer também foi pesado obtendo-se $m_{b}=34 \pm 1 \mathrm{~g}$, resultando numa massa de água de $m_{A}=110 \pm 1$ g. A seguir essa amostra de água foi aquecida dentro do calorímetro de acordo com o arranjo esquematizado na figura 2 Depois de feita a medida, o processo foi refeito adicionando-se uma peça de latão com massa $m_{M}=200 \pm 1$ g e a nova

\footnotetext{
${ }^{4} \mathrm{~A}$ medida teve que ser feita indiretamente a partir de um molde de água congelada dentro do calorímetro.
}

massa d'água obtida foi de 87,0 $\pm 0,2 \mathrm{~g}$ Desta forma o volume de água mais o volume da peçd ${ }^{6}$ totalizou 110,5 $\mathrm{ml}$, um desvio menor do que $0,2 \%$.

A coleta de dados se deu então a partir da análise dos vídeos obtidos. Nas filmagens observa-se que o mesmo valor de temperatura transcorre por um considerável intervalo de tempo, que variava de um sistema ao outro. Para se determinar então a qual instante corresponderia uma dada leitura de temperatura estabeleceu-se o seguinte método: anota-se o valor do tempo cronometrado pelo vídeo no primeiro instante em que aparece cada valor de temperatura no multímetro. Em seguida, considerando-se a linearidade na variação de $T(t)$ (conforme a equação 8), assume-se que a temperatura apresentada no monitor do multímetro ocorre efetivamente no ponto médio do intervalo temporal adotado. Esse procedimento é exemplificado pela tabela 8 Para o conjunto de dados apresentado na tabela a temperatura de $27{ }^{\circ} \mathrm{C}$ ocorre em $t=73,5 \mathrm{~s}$.

Adotando-se esse método então a incerteza na medida das temperaturas reduz-se drasticamente, dependendo em última análise à incerteza nas medidas de tempo. Neste caso, a incerteza recai sobre a determinação do

Tabela 8: Exemplo de leitura dos dados a partir dos vídeos. São atribuídos às leituras de temperatura os valores médios dos intervalos temporais como instante de sua ocorrência.

\begin{tabular}{cccc}
\hline Temperatura $\left({ }^{\circ} \mathrm{C}\right)$ & $t_{i}(\mathrm{~s})$ & $t_{f}(\mathrm{~s})$ & $t_{\text {med }}(\mathrm{s})$ \\
\hline 27 & 42 & 105 & 73,5 \\
28 & 105 & 156 & 130,5 \\
\hline
\end{tabular}

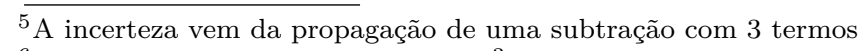
${ }^{6}$ A partir da densidade de $8,50 \mathrm{~g} / \mathrm{cm}^{3}$ para o latão. 
início e do final de cada intervalo. Pode-se atribuir a cada extremo a incerteza de $1 \mathrm{~s}$ - que é o valor do passo na leitura no cronômetro dos vídeos analisados. Assim a incerteza na temperatura vem exclusivamente da incerteza no intervalo de tempo e, de acordo com [5], pode ser propagada pela expressão

$$
\sigma_{T}=\left|\frac{d T}{d t}\right| \sigma_{t}=\alpha \sigma_{t}
$$

onde $\alpha$ é dado pelas equações 11 e 8 , e pode ser obtido com um ajuste dos parâmetros de reta aos pontos selecionados. Em geral, ao utilizar-se o Método do Mínimos Quadrados (MMQ) para ajustes de reta é necessário o conhecimento das incertezas nos valores da variável dependente. Portanto, para se obter um ajuste final, pode-se empregar um processo recursivo, onde no primeiro caso faz um ajuste de reta com MMQ utilizando uma valor constante para as incertezas em $T\left(\sigma_{T}=1{ }^{\circ} \mathrm{C}\right.$, por exemplo), obtém-se o valor de $\alpha$ e em seguida recalcula-se o valor de $\sigma_{T}$ para se proceder então com o ajuste definitivo, o qual será de fato utilizado para a análise dos dados.

Os dados obtidos com a análise dos vídeos estão apresentados no gráfico da figura 4. Percebe-se da relação dos pontos e suas incertezas com os seus respectivos ajustes que a metodologia de análise adotada e as reduzidas incertezas dela proveniente foram satisfatórias. Os resultados de $\chi^{2}$ também ajudam a corroborar essa conclusão.

Com os ajustes aos pontos experimentais foram obtidos os seguintes valores de coeficiente angular,

$$
\begin{aligned}
& \alpha_{1}=(17,82 \pm 0,11) \cdot 10^{-3}{ }^{\circ} \mathrm{C} / \mathrm{s} \\
& \alpha_{2}=(16,89 \pm 0,08) \cdot 10^{-3}{ }^{\circ} \mathrm{C} / \mathrm{s}
\end{aligned}
$$

A partir dos quais podemos então calcular o calor específico $c_{M}$ seguindo a prescrição indicada nas equações 9 e 11 . Substituindo na equação 9 os valores de $m_{M}$ fornecido acima e $\Delta m_{A}=-23,3 \pm 0,2 \mathrm{~g}$ e $P=9,54 \pm 0,11 \mathrm{~W}$ obtivemos para o calor específico da peça com sua respectiva incerteza o valor

$$
c_{M}=489 \pm 192 \mathrm{~J} /\left(\mathrm{kg}^{\circ} \mathrm{C}\right)
$$

Este resultado obviamente é compatível com o valor tabelado para o latão, mas é um resultado insatisfatório devido ao elevado valor de incerteza obtida. Da forma como executado, esse método experimental não deve ser priorizado, pelo menos não em termos de resultados quantitativos, embora seja bastante rico em termos didáticos, pois possui preparo e procedimento experimental mais elaborado e metodologias de análise de dados mais sofisticadas.

\section{Discussão}

Apesar de não estar inicialmente no planejamento deste experimento é possível comparar uma das medidas de capacidade térmica do método "padrão" com uma das medidas do método usando o efeito Joule. Pode-se comparar o valor obtido de $\overline{C_{c a l}}(g)$ (dados da tabela 1) e $C_{c a l}(v 54)$, pois a massa média de água no primeiro caso foi $\left\langle m_{A}\right\rangle=53 \pm 3 \mathrm{~g}$ e no segundo caso $m_{A}=54 \pm 1 \mathrm{~g}$. Para essas medidas obtivemos, respectivamente, capacidades térmicas de $18 \pm 3 \mathrm{~J} / \mathrm{K}$ e $C_{\text {cal }}(v 54)=73 \pm 5 \mathrm{~J} / \mathrm{K}$, mostrando um resultado $\sim 4$ vezes maior para o método do efeito Joule. Com base no que já foi discutido na seção 5.1 isso é uma indicação de que a troca de calor com o ambiente foi maior neste método. Com efeito, se analisarmos o balanço de energia, o calor fornecido pelo resistor $Q_{R}$ no intervalo de tempo $\Delta t$ é dividido entre a água, o calorímetro e o ambiente como

$$
Q_{R}+Q_{A}+Q_{c a l}+\delta Q=0
$$

Como a hipótese é de que há equilíbrio térmico a todo instante, a variação de temperatura $\Delta T$ é a mesma para todos os participantes, exceto o ambiente. Assim, a expressão acima redundaria na equação 14 . onde o termo $\delta Q$ é proporcional ao calor trocado com o ambiente. A equação 14 pode ser reescrita como

$$
C_{c a l}=C_{T}-m_{A} c_{A}-\delta C
$$

Ficando evidente que, quanto maior o valor absoluto do calor trocado com o ambiente, maior será a superestimação de $C_{\text {cal }}$ se $\delta Q$ (ou $\delta C$ ) for desprezado.

Com efeito, cabe um último comentário acerca de $\delta Q$ : ele é proporcional à diferença de temperatura entre o conteúdo do calorímetro e o ambiente. Se formos pensar apenas em termos da potência dissipada pelas paredes do calorímetro vemos que [2]

$$
P_{d i s}=k \frac{A}{L}\left(T_{>}-T_{<}\right)
$$

Onde $k$ é a condutividade térmica das paredes do calorímetro, $L$ sua espessura e $A$ a área sujeita à transferência de calor. $T_{>}$e $T_{<}$são a temperaturas maior e menor, respectivamente. Note que quanto maior a diferença de temperatura, maior a potência dissipada (maior $\delta Q$ ). Com essa expressão fica também evidente que quanto maior a superfície de contato entre a água e o calorímetro, maior a troca com o ambiente, corroborando a preocupação em se manter a altura do volume d'água sempre igual.

O calor poderia também ser perdido por irradiação, mas consideramos esse efeito desprezível pois a temperatura na superfície externa do calorímetro permaneceu sempre igual à temperatura ambiente.

Uma possibilidade para minimizar o efeito de $\delta Q$ nas medidas é adotar um procedimento em que a água seja colocada no calorímetro inicialmente a $3^{\circ} \mathrm{C}$ ou $4^{\circ} \mathrm{C}$ abaixo da temperatura ambiente e deixada $\sim 30 \mathrm{~s}$ para termalizar com o calorímetro e então ligar a resistência, fazendo medidas de temperatura e cronometrando o tempo até se atingir uma temperatura $3^{\circ} \mathrm{C}$ ou $4^{\circ} \mathrm{C}$ acima da ambiente. Desta maneira, além de se ter o valor 


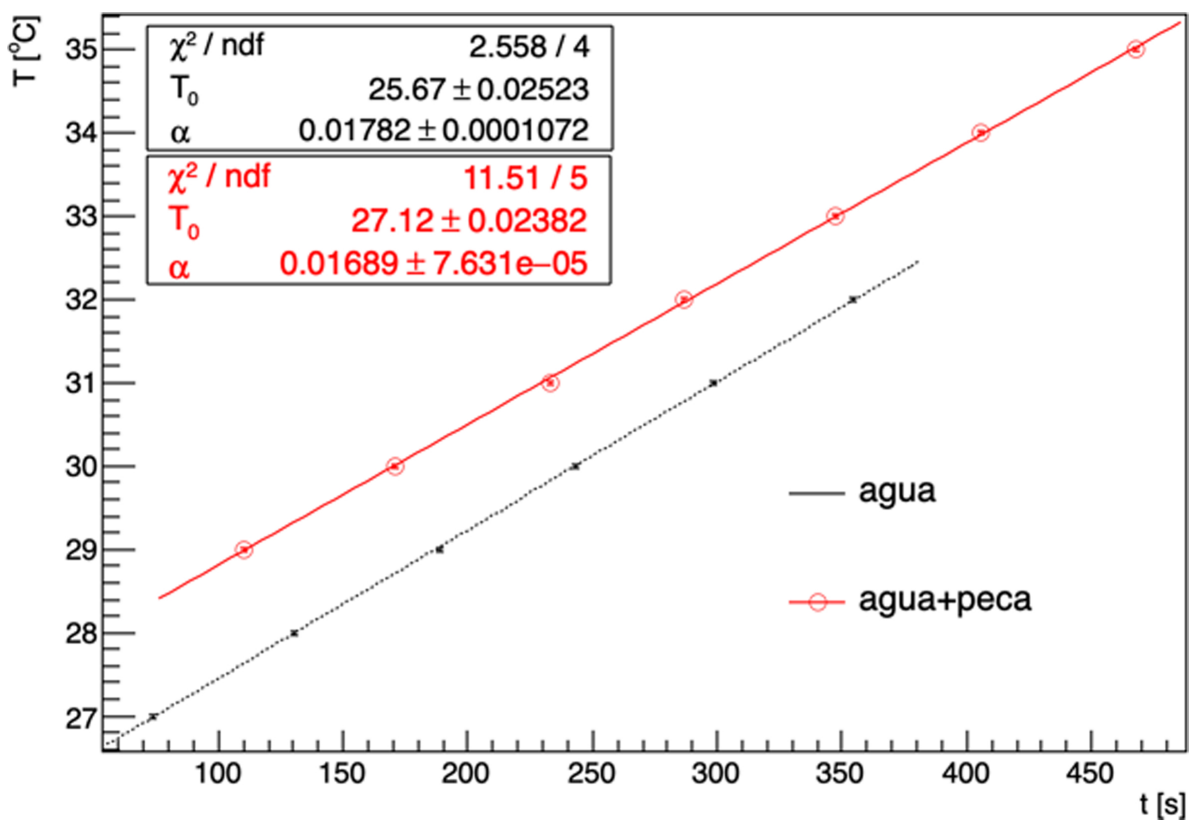

Figura 4: Evolução temporal da temperatura da água para os conjuntos com (símbolos circulares) e sem a peça metálica (símbolos quadrados) e seus respectivos ajustes de reta. Os parâmetros do ajuste aos dados sem a peça estão na caixa superior (à esquerda) e para os dados com a peça estão na caixa inferior (também à esquerda).

absoluto da potência dissipada sempre baixo por conta da pequena diferença de temperatura, o sinal de $\delta Q$ se inverte no processo, sofrendo um cancelamento se não total, ao menos significativo. Essa possibilidade não pôde ser testada neste trabalho.

\section{Conclusão}

Testamos várias possibilidades para experimentos de calorimetria em laboratórios didáticos, sempre com o objetivo de encontrar os procedimentos mais seguros em termos de resultados e efeito pedagógico. Com isso procuramos definir e quantificar todas as variáveis relevantes a esse tipo de experimento. Buscamos explorar algumas variáveis "ocultas" através da formulação e teste de hipóteses a elas associadas.

Foram testadas hipóteses para os efeitos da não quantificável troca de calor com o ambiente e de variação da estimativa da capacidade térmica do calorímetro como função da quantidade de água. Da primeira hipótese o teste resultou na conclusão de que os experimentos em que a água tem temperatura inicial significativamente maior do que a ambiente incorrem na maior troca de calor com o meio externo, significando a maior superestimação possível para o valor da capacidade térmica. Concluímos ainda que esse efeito, quando muito exacerbado, pode resultar em valores negativos para calor específico do material em teste. Portanto a utilização de procedimentos com água inicialmente quente não devem ser adotados.

Ainda em relação à primeira hipótese acima, embora possamos concluir que o procedimento com a água inicialmente fria tem impacto menor em termos de superes- timação da capacidade térmica do calorímetro, ele deve ser desfavorecido em relação aos procedimentos em que - caso o material em teste seja uma peça metálica - a amostra é que está inicialmente aquecida. Testes com a peça inicialmente resfriada não deram bons resultados e testes futuros, como o de se agitar continuamente o calorímetro, devem ser realizados.

Em relação à segunda hipótese obtivemos um resultado no limite da compatibilidade para o teste com duas amostras de água. Existe uma aparente tensão entre os resultados, indicando que possivelmente a estimativa de capacidade térmica pode sim variar com a quantidade de água utilizada. Essa possibilidade é reforçada pela análise realizada sobre a equação 20. No entanto foi também observado que a capacidade térmica do calorímetro pode ser considerada irrelevante quando os procedimentos adotados utilizam a água inicialmente à temperatura ambiente.

Quanto à metodologia que utiliza o efeito Joule pudemos concluir que é um procedimento experimental bastante rico em termos pedagógicos, tanto na questão da elaboração do arranjo, quanto com os cuidados durante as medidas, quanto à redução e análise de dados. No entanto em termos de resultados experimentais o método ficou abaixo do desempenho esperado. Uma das razões aventadas para esse fato é a questão da troca de calor com o ambiente pode ser significativa o que implicaria na superestimação do valor do calor específico. A principal fonte de incertezas na metodologia de análise adotada foi a incerteza do parâmetro de ajuste referente ao coeficiente angular, propagado para a incerteza da variável $\Sigma$. A forma hipotetizada para melhorar esse método é o 
de tomar a variação de temperatura da água em torno da temperatura ambiente, de preferência de alguns graus abaixo a alguns graus acima desta, de forma a minimizar - ou até cancelar - as trocas com o ambiente.

Ao leitor interessado em elaborar um roteiro experimental de calorimetria, os resultados deste trabalho sugerem a adoção de procedimento com água inicialmente à temperatura ambiente e com uma peça metálica aquecida para obtenção de resultados mais confiáveis e com menores flutuações estatísticas.

\section{Agradecimentos}

Os autores realizaram as medidas em um dos laboratórios didáticos da Universidade Federal do ABC, e agradecem o auxílio de seus técnicos, em especial de Cesar M. M. Pereira, pela engenhosa medida do diâmetro do calorímetro.

Os autores agradecem à CAPES e à FAPESP (processo 2018/10922-6) pelo apoio financeiro.

\section{Referências}

[1] H.M. Nussenzveig, Curso de Física Básica - 2: Curso de Física basica: fluidos, oscilações e ondas, calor (Editora Edgard Blücher, São Paulo, 2002)

[2] R.A. Serway e J.W. Jewett, Princípios De Física - Vol. Ii - Oscilações, Ondas (Editora CENGAGE DO BRASIL, São Paulo, 2015)

[3] Instituto de Física, Apostila da disciplina Laboratório de Física I (4310256), Calorimetria, ajuste da reta e propagação de erros, disponível em https://edisciplinas. usp.br/mod/resource/view.php?id=1557702 (2017).

[4] Universidade Federal do ABC, Roteiro Experimental de Fenômenos Térmicos (BCJ0205) - Calorimetria, disponível em http://tiny.cc/55et8y (2019).

[5] J.H. Vuolo, Fundamentos da teoria dos erros (Editora Edgard Blücher, São Paulo, 1996).

[6] C.M. e A. Gaspar, Revista Brasileira de Ensino de Física 25, 45 (2003). 